\title{
Psychopathological Verbal Expression of Self-Perceived Stress in Three Groups of Psychotic Patients
}

\author{
N. Jimeno Bulnes ${ }^{\mathrm{a}}$, A. Jimeno Valdés ${ }^{\mathrm{a}}$, M.L. Vargas Aragón ${ }^{\mathrm{b}}$, \\ M.N. López Fernández ${ }^{a}$ \\ ${ }^{a}$ Medical School, University of Valladolid, and ${ }^{b}$ Psychiatric Hospital of Reus, Spain
}

\begin{abstract}
Self-perceived stress in 293 psychotic patients (schizophrenic, toxic and brief reactive psychoses) and a control group of 40 sane individuals was evaluated by means of the Frankfurt Complaint Questionnaire. For this purpose, scores obtained in 6 'complementary items' of the third version of this questionnaire were studied, both in global and in detailed form. These items reflect coping mechanisms exerted towards situations perceived as stressful which can produce clinical manifestations similar to the wellknown 'negative symptoms' of schizophrenia. Results show that self-perceived stress in all groups of patients is significantly higher than in the control group. In contrast, no significant differences among the three groups of patients are obtained. In conclusion, we point out the relevance of studying the psychotic patient's self-perceived stress in order to detect and minimize or even avoid the patient's risk situations, independent of his/her diagnosis. This will be especially useful to obtain optimal conditions for rehabilitation.
\end{abstract}

\section{Introduction}

In a considerable effort to understand and study effectively the psychopathology of the psychotic patient, or at least of the patient diagnosed with schizophrenia, a growing number of works are continuously being published. A great deal of them focus on the symptomatology exhibited by the patient, and are based either on the phenomenological contributions of Kraepelin [1], Bleuler [2] or Schneider [3], or on scores obtained through different scales such as the Scale for the Assessment of Positive Symptoms and the Scale for the Assessment of Negative Symptoms of Andreasen [4, 5] or the Positive and Negative Syndrome Scale of Kay et al. [6]. In this way, clinical manifestations collected objectively just as they are observed can even be quantified by the explorer. This procedure allows detecting, for instance, the presence of paranoid ideas, hallucinations, affective flattening or social isolation.

In other cases, different cerebral explorations, both morphological and functional, are used in order to clarify pathogenetical mechanisms involved in neurobiological as-

\section{KARGER}

E-Mail karger@kargerch Fax + 41613061234 http://www.karger.ch
(C) 1997 S. Karger AG, Basel 0254-4962/97/0301-0039\$12.00/0
Natalia Jimeno Bulnes

Pío Baroja 126

Coto del Cardiel

E-47150 Viana de Cega, Valladolid (Spain) 
pects of the illness. In this section, neuropsychological studies concerning performance in tests, e. g. of attention, memory and reaction time, could also be included.

There is, however, a chance of missing the direct collection of experiences suffered by the patient, especially in intercritical stages of the illness. This is perhaps due to the difficult quantifying or comparison with other patients or diagnostic groups. Experiences of this kind in functions such as visual perception, attention and language have already been described by the group of McGhie and Chapman [7-11] in initial stages of the illness, and have been the main objective of German research groups of Süllwold in Frankfurt, Huber and Gross in Bonn, and Klosterkötter in Aachen [12-22].

These and other authors recognize firstly the presence in those patients of the so-called 'substrate-near basic symptoms' (Substratnahe Basissymptome), which are 'manifold dynamic and cognitive deficiencies' that 'constitute the primary symptoms of schizophrenia, that is, they are nearer to the hypothesized somatic substrate than the complex psychotic phenomena which are formed and modified by secondary processes' [13]. Thus these symptoms are usually perceived and expressed as deficits, losses or disorders by chronic psychotic patients; they diminish the patient's ability to deal with the demands of daily living [22]; and are hypothetically ascribed to impairments of selective information processing, lack of hierarchies of habituation, and genetically determined biochemical disturbances in the limbic system $[13,17]$.

Among various evaluation instruments of such symptomatology is Süllwold's Frankfurt Complaint Questionnaire (Frankfurter Beschwerde-Fragebogen, FBF) $[19,21]$, whose use was introduced in Spain by our group 10 years ago [23-26]. This psychopathological instrument, evaluating symptoms of mental functions such as perception and thought, was developed from spontaneous complaints of schizophrenic patients collected in a review of hundreds of clinical records. In its third version it includes questions dealing not only with basic symptoms of 10 mental functions such as perception, thought and language, but also with mechanisms and strategies voluntarily developed by the patient in order to feel better, such as working slowly or talking little.

In the present paper we assume that these mechanisms are aimed at minimizing and avoiding situations that patients perceive as stressful. Until now, stress suffered by the patient has been studied both through the presence of all sorts of dramatic life events, and through the patient's response to this stress [27, 28, for a review see 29]. In this sense, the concept of expressed emotion [30] has received great interest. We hypothesize that self-perceived stress is higher in schizophrenic patients than in normal subjects.

Thus, the main purpose of this paper is to evaluate the stress level experienced by different groups of psychotic patients and a control group, by means of the FBF, in order to study its possible implications in clinical practice, especially in the therapeutic field.

\section{Materials and Methods}

Materials

All patients were hospitalized at least once with an acute psychotic syndrome in the Psychiatry Unit of the University Hospital of Valladolid (Spain) between 1989 and 1992. Patients were diagnosed by the clinician in charge according to DSM-III-R criteria. Table 1 shows the inclusion and exclusion criteria in the study.

A total of 293 patients were recruited, and divided into the following diagnostic groups: (1) schizophrenic psychoses (SP), with patients diagnosed according to the DSM-III-R system; this group con-

40

Psychopathology 1997;30:39-48
Jimeno Bulnes/Jimeno Valdés/Vargas Aragón/ López Fernández 
Table 1. Inclusion and exclusion criteria of the study

\section{Inclusion criteria}

(1) Inpatients of the Psychiatry Unit of the University Hospital of Valladolid who were diagnosed to be suffering from one of the following either alone or in association with other disorders according to DSM-III criteria:

(a) Delirious substance use disorder (292.11)

(b) Schizophrenia (295.xx)

(c) Brief reactive psychosis (298.90)

(d) Schizophreniform disorder (295.40)

(2) Age between 16 and 55 years, both included

(3) A minimum of reading comprehension skills and willingness to cooperate

\section{Exclusion criteria}

(1) Suffering from organic-cerebral or serious somatic pathology

(2) Age under 16 or over 55

(3) Low comprehension skills or not enough willingness to cooperate

Table 2. Sociodemographic and clinical data of the sample

\begin{tabular}{|c|c|c|c|c|c|c|}
\hline \multirow[b]{2}{*}{ Sex } & \multicolumn{2}{|l|}{ SP } & \multicolumn{2}{|c|}{$\mathrm{TP}$} & \multicolumn{2}{|c|}{$\mathrm{AP}$} \\
\hline & & & & & & \\
\hline Male & 93 & $(75.61)$ & 56 & $(86.15)$ & 49 & $(46.67)$ \\
\hline Female & 30 & $(24.39)$ & 9 & $(13.85)$ & 56 & $(53.33)$ \\
\hline Mean age & 27. & \pm 7.0 & 24. & \pm 5.6 & 27.9 & \pm 11.4 \\
\hline \multicolumn{7}{|l|}{ Marital status } \\
\hline Single & 119 & $(96.75)$ & 60 & $(92.31)$ & 75 & (71.43) \\
\hline Married & 3 & $(2.44)$ & 3 & $(4.62)$ & 27 & $(25.71)$ \\
\hline Sep./divorced & 1 & $(0.81)$ & 2 & $(3.08)$ & 3 & $(2.86)$ \\
\hline Others & 0 & $(0)$ & 0 & $(0)$ & 0 & $(0)$ \\
\hline \multicolumn{7}{|l|}{ Educational level } \\
\hline Primary & 12 & $(9.76)$ & 16 & $(24.62)$ & 14 & (13.33) \\
\hline Middle school & 58 & $(47.15)$ & 32 & $(49.23)$ & 48 & $(45.71)$ \\
\hline High school & 38 & $(30.89)$ & 17 & $(26.15)$ & 31 & $(29.52)$ \\
\hline University & 17 & $(13.82)$ & 0 & $(0)$ & 12 & (11.43) \\
\hline \multicolumn{7}{|l|}{ Employment status } \\
\hline Active & 51 & $(41.46)$ & 20 & $(30.77)$ & 68 & (64.76) \\
\hline Unemployed & 36 & $(29.27)$ & 25 & $(53.85)$ & 28 & $(26.67)$ \\
\hline Trans. work. inc. & 7 & $(5.69)$ & 3 & $(4.62)$ & 8 & $(7.62)$ \\
\hline Perm. work. inc. & 29 & $(23.58)$ & 7 & $(10.77)$ & 1 & $(0.95)$ \\
\hline Retired & 0 & $(0)$ & 0 & $(0)$ & 0 & $(0)$ \\
\hline
\end{tabular}

Figures in parentheses indicate percentages.

tained 123 patients; (2) toxic psychoses (TP), with 65 cases, including not only patients with substanceinduced delirious disorders but also psychotic patients with previous or current substance use, and (3) acute psychoses (AP), which comprised brief reactive and schizophreniform psychoses; 105 patients.

Some sociodemographic data of the sample are shown in table 2, including sex, age, marital status, education and employment status. A clear prevalence of men is found in SP and TP (75.61 and 
$86.15 \%$, respectively), but not in AP, where more than half of the patients are women (53.33\%). The average age is very similar in the SP and AP groups ( $27.7 \pm 7.0$ and $27.9 \pm 11.4)$, while patients in the TP group are somewhat younger $(24.1 \pm 5.6)$. Patients of the three diagnostic groups are usually single and have reached a middle educational level ( 8 years). The active working status is more frequent in $\mathrm{SP}$ and AP, and unemployment in TP, with percentages close to $50 \%$ each.

The control group (CG) consisted of 40 individuals of both sexes who lacked any history of psychiatric consultation or treatment and who had been taken from the general, hospitalized, non-psychiatric population. The questionnaire was explained to the subjects, and only those willing to take part in the study were selected. The number allows applying statistical techniques to compare results obtained in the CG with the mentioned groups of patients. The sex distribution of the CG is $50 \%$ (20 cases each) and the mean age is $25.58 \pm 4.79$ years.

The FBF, which, as previously mentioned, was designed by Süllwold based on the research of Poljakov [31], has undergone two different revisions so far. The first version [19] contained 103 items distributed in 12 descriptive subscales; the second, with only 70 items taken from the first, was never published; and the third [21], used in this study, has 98 items and several complementary items. The first and third versions of the questionnaire have been translated into Spanish by our group [25, 32].

In the last version, the first 98 items correspond to 10 descriptive scales or categories (such as loss of control, and simple perception). The patient has enough space to note down some other complaints not specifically collected in the questionnaire. Only the 6 complementary items in the Spanish version, headed by the sentence I find it helpful and I feel better if ..., express some coping mechanisms towards a number of situations possibly perceived as stressful by the patient. The content of the items used in this paper are thus expressed:

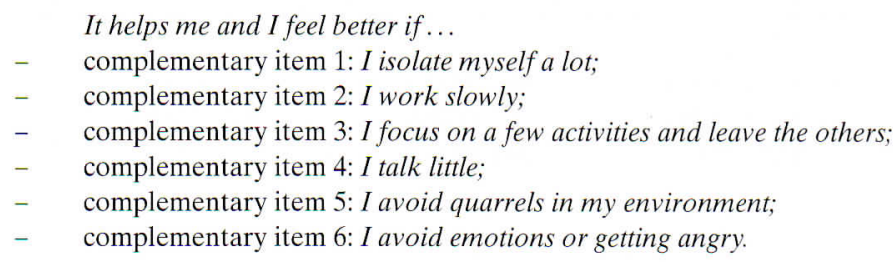

Two items (5 and 6) mention hyperstimulative situations of the patient: too many quarrels (i.e. noise, lights and visits) and too many emotions or, more specifically, irritations, experienced by the patient. Whether the patient feels himself better when isolated or talking little (items 1 and 4) is also evaluated; that can perhaps blend in the well-known negative symptoms of social withdrawal and autism, which could sometimes be interpreted as coping mechanisms towards other more or less voluntary symptoms developed by the psychotic. In any case, when the patient admits employment-related or social demands of the environment, he may prefer working slowly or concentrating himself/herself on a few activities only (items 2 and 3 ).

All questions of the FBF have two possible answers (yes or no). Four different data analyses can then be made: (1) an item score, of patients who answer affirmatively to each item; (2) a scale sore, obtained in each of the descriptive scales or categories and in the complementary items; (3) a total score, in relation to the 98 items, and (4) a factor score, which corresponds to the cluster statistical analysis.

Our experience shows that this is welcomed by the patient, who quickly identifies in the items experiences and sensations that can hardly be verbally expressed, and that are not usually studied in classic psychopathology.

This work focuses on the results obtained in the complementary items, which reflect the psychopathological verbal expression of the patient's self-perceived stress.

\section{Method}

Patients completed the FBF after remission of the acute outbreak, as either inpatients or outpatients. Recommendations of the author [21] in the application of the FBF were carefully followed. In order to verify our hypothesis and reach the main purpose of this paper, we carried out a descriptive study with scores obtained in the FBF complementary items and a contrast of mean scores among the three different groups of psychotic patients. The $\chi^{2}$ test was used for the processing of the data. 
Table 3. Affirmative answers to the complementary items (CIs) of the FBF

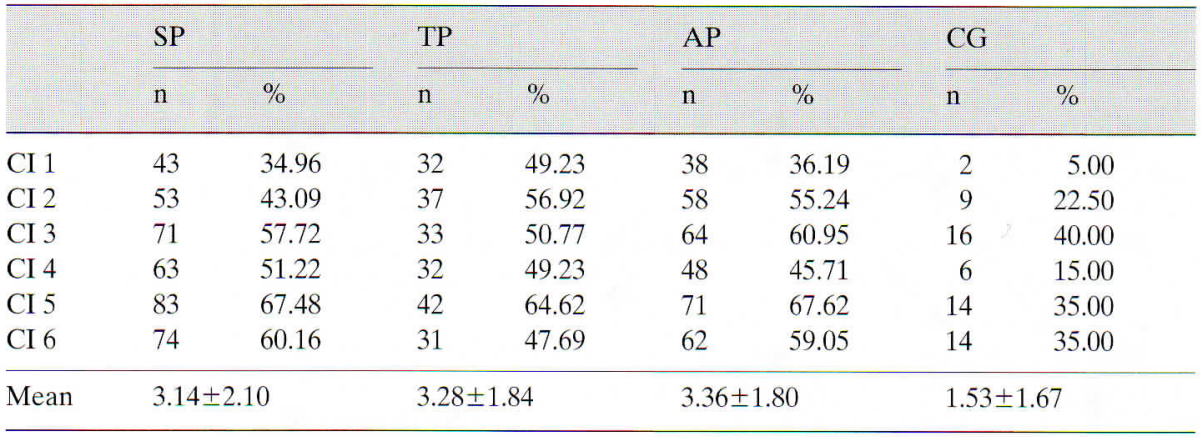

Table 4. Significance levels of the complementary items (CIs) of the FBF

\begin{tabular}{lllllll}
\hline & SP-TP & SP-AP & TP-AP & SP-CG & TP-CG & AP-CG \\
\hline CI 1 & NS & NS & NS & $* * * *$ & $* * * *$ & $* * * *$ \\
CI 2 & NS & NS & NS & $*$ & $* * * *$ & $* * * *$ \\
CI 3 & NS & NS & NS & NS & NS & $*$ \\
CI 4 & NS & NS & NS & $* * * *$ & $* * * *$ & $* * * *$ \\
CI 5 & NS & NS & NS & $* * * *$ & $* * *$ & $* * * *$ \\
CI 6 & NS & NS & NS & $* * *$ & NS & $* * *$ \\
Mean & NS & NS & NS & $* * * *$ & $* * * *$ & $* * * *$ \\
\hline
\end{tabular}

NS $=$ Not significant.

${ }^{*} \mathrm{p}<0.05,{ }^{* * *} \mathrm{p}<0.02, \quad \mathrm{p}<0.01,{ }^{* * * * *} \mathrm{p}<0.005$.

\section{Results}

Tables 3 and 4 show results obtained in the FBF complementary items from the three different groups of patients and from the CG. These data are graphically displayed in figures 1 and 2 .

Firstly, almost half of the SP or AP patients replied in the affirmative to every complementary item of the FBF, except perhaps to item 1 (I find it helpful and I feel better if I isolate myself a lot, 34.96 and $36.19 \%$, respectively). In all diagnostic groups considered item 5 (it helps me and I feel better if I avoid quarrels in my environment) is most frequently present (from $64.92 \%$ in the TP group to $67.48 \%$ in the SP group). No statistically significant differences among the diagnostic groups were detected.

In the CG, item 3 (It helps me and I feel better if I focus on a few activities and leave the others) prevails, appearing in $40.00 \%$ of the cases, while item 1 is the least frequent, detected in only 2 cases $(5.00 \%)$. As displayed in table 4 , most items are significantly higher in psychotics when comparing patients with the CG. For example, the three different comparisons (SP-CG, TP-CG and AP-CG) show $\mathrm{p}<0.005$ for both items 1 and 4 (in item 1: SP-CG, $\chi^{2}=12.10$, d.f. 1; TP-CG $\chi^{2}=20.15$, d.f. 1 ; AP-CG, $\chi^{2}=12.59$, d.f. 1; in item 4: SP-CG, $\chi^{2}=14.77$, d.f. 1; TP-CG, $\chi^{2}=11.13$, d.f. 1; AP-CG, $\chi^{2}=11.40$, d.f. 1). 


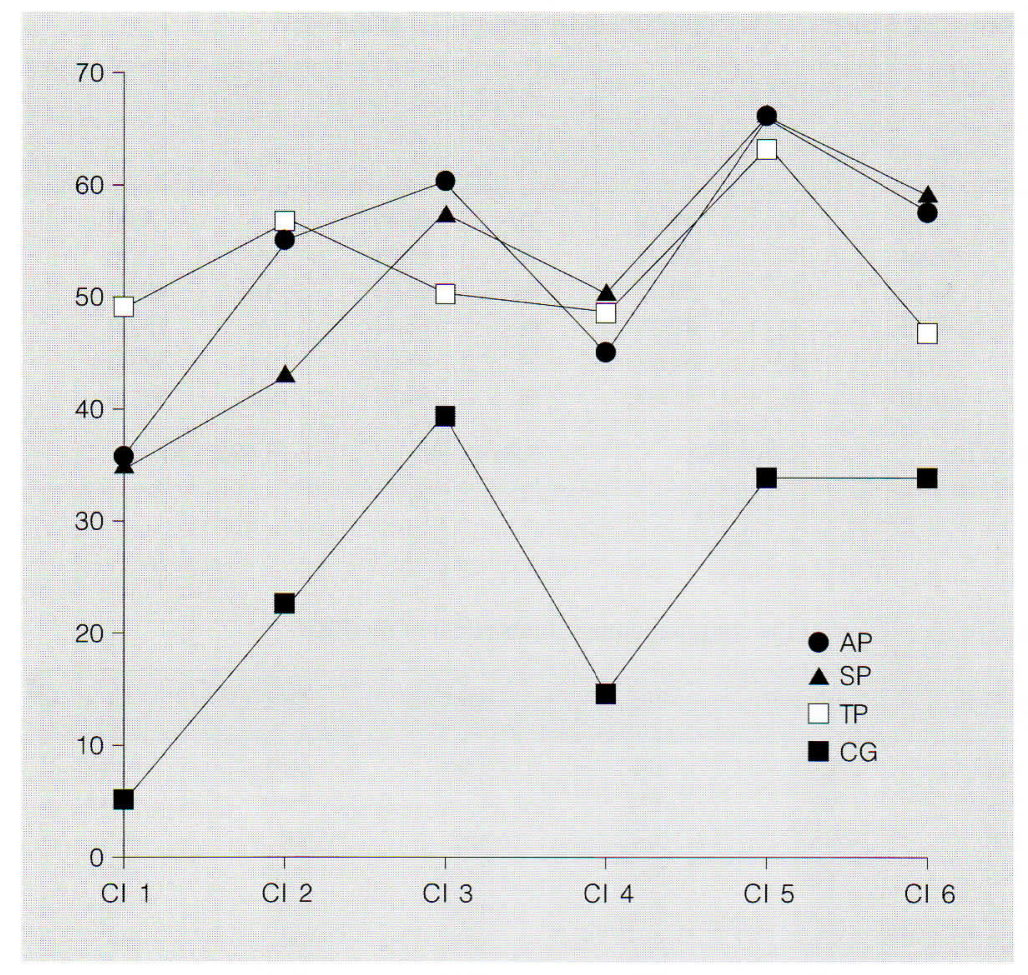

Fig. 1. Affirmative answers to the complementary items (CIs) of the FBF.

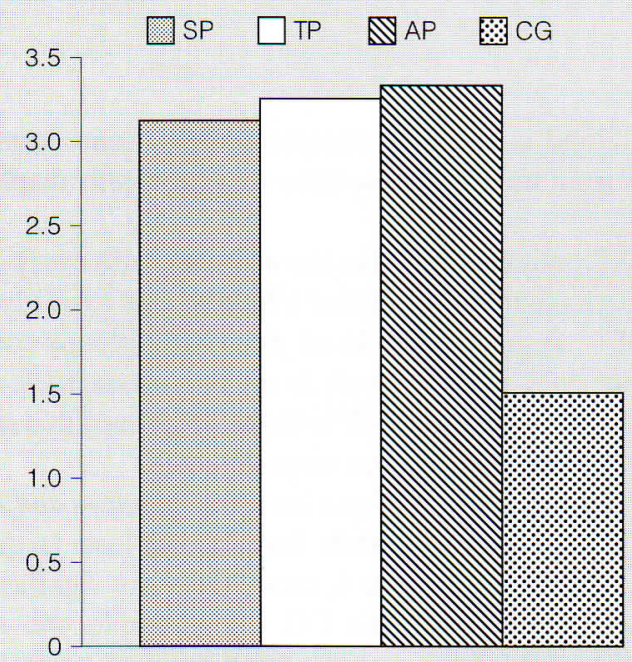

Fig. 2. Average scores to the complementary items of the FBF. 
The average scores in the 6 complementary items are over 3 in the three diagnostic groups (3.14 $\pm 2.10,3.28 \pm 1.84$ and $3.36 \pm 1.80$ in the SP, TP and AP, respectively). These figures go down to $1.53 \pm 1.67$ in the CG. No statistically significant differences are observed when comparing these averages among the psychotic groups. In contrast, these are detected in the comparison between patients and the CG, with $\mathrm{p}<0.005$ in all three cases (SP-CG, $\chi^{2}=19.14$, d.f. 6 ; TP-CG, $\chi^{2}=27.11$, d.f. 6 ; $\mathrm{AP-CG}, \chi^{2}=30.58$, d.f. 6 ).

\section{Discussion}

The first aspect of our discussion is the concept and measurement of stress, as well as the extent to which the complementary items of the FBF can quantify the level of self-perceived stress in a given person. Several definitions of the term have been proposed. For example, for Spring [33] stress may be considered firstly as a response involving disruption in homeostasis, and secondly as a stimulus with objectively specifiable properties. Thirdly, stress is also defined interactionally with reference to characteristics of the individual and the life context.

We consider the third definition to be the most adequate for our investigation as it points to the subjective response to stress, independently of the circumstances or stimuli that generate it. The same stimulus can produce different reactions in different persons, or even in the same person on different occasions. This implies that the main source of information should be the subject himself/herself, although data provided by relatives are also to be considered.

Adopting one or another opinion undoubtedly implies certain advantages and disadvantages, which have been analyzed in detail by Norman and Malla [29]. In relation to the subjective approach, we may see several advantages: the first is to avoid the recall bias existing in the method of stressor identification that could be expressed by the recognition of an excessive number of stressors. In contrast, cognitive impairments make this task unreliable.

Furthermore, according to this paper one must not forget that stressors in ordinary circumstances and chronic difficulties are more likely to influence schizophrenics than unusual and major life changes. The patient's response not only to past or present events but also to future events should be taken into account. In any case, the main disadvantage of the subjective approach is the significant risk of overestimating the influence of stress on any illness, including schizophrenia. This can be due to the interaction between symptoms and stress, so that a worsening of symptoms may result in a patient experiencing more stress.

Does the FBF assess the stress perceived by the patient when faced with certain situations? Strictly speaking, the inventory collects some 'self-healing strategies' that the patient develops for compensation when experiencing certain danger signals [34]. These and other strategies, also called 'autoprotective efforts', are performed consciously and are focused primarily on reducing emotional tension arising from the recognition of basic disorders [35], ultimately the stress level developed towards certain circumstances. Minimizing or avoiding stress reduces the risk of psychotic relapses, as several authors have pointed out [22, 36-39].

To our knowledge, works in the world literature that analyze data obtained from the complementary items of the FBF are rather scanty. This can be attributed to the fact that the basic symptoms theory has had no wide acceptance as yet and that its corre- 
sponding instruments of evaluation have not been broadly disseminated. Nevertheless, in a study of 229 schizophrenic patients, Süllwold [21] finds affirmative answers to the complementary items, from $27.1 \%$ in item 4 (It helps me and I feel better if I talk little) to $65.9 \%$ in item 5 (It helps me and I feel better if I avoid quarrels in my environment). Thus our results in three groups of psychotic patients corroborate those obtained in schizophrenics by the author of the questionnaire.

In relation to the item scores, and as part of a greater project on the FBF, Jimeno Bulnes et al. [32] determined, in the same sample of 293 psychotic patients, that $34.1 \%$ answer affirmatively to 2 items, $65.9 \%$ to 4 and $86.3 \%$ to 5 items. Mean scores of the complementary items in our paper are very similar to those obtained by Jimeno Bulnes [40, 41] in 120 psychotic patients, 40 of whom had been diagnosed as having schizophrenia, 40 as having toxic psychoses and 40 as having brief reactive psychoses. Indeed, this investigation produced mean scores between $3.10 \pm 1.50$ in subjects with toxic psychoses and $4.18 \pm 2.22$ in those with brief reactive psychoses. Patients of both groups also answered more frequently to the aforementioned item 5 .

Figures for psychotic patients in our study are slightly higher than the mean scores of the sample of Vargas [42] and Vargas et al. [43, 44], which consisted of 58 patients who had been treated as inpatients because of psychotic symptomatology. Their progress is studied 3 times per year (every 4 months) using, among other tests, the FBF. The results show that complementary items are more frequent in schizophrenics (2.98) and not as frequent in brief reactive psychoses (1.82). In a previous study of 30 psychotic inpatients, Jimeno Bulnes [45] and Jimeno Bulnes et al. [46] obtained slightly higher scores for toxic psychoses (4.50) and similar scores for the other groups (schizophrenic, brief reactive and bipolar psychoses) for the complementary items. Other studies performed by our research group [47] point out that these items show similar frequencies in both sexes $(3.70 \pm 1.58$ in men and $3.50 \pm 2.82$ in women $)$.

In relation to the $\mathrm{CG}$, results from our previous work [45] reflect that the presence of these items was significantly more unusual in sane subjects than in groups of patients $(\mathrm{p}<0.001)$, which agrees with the results displayed in this article.

In summary, one can deduce from our data that coping mechanisms towards stressful situations, as experienced by patients, are present to an important and a similar degree during the acute outbreak in all groups of psychotic patients studies. That is, the questionnaire evaluates unspecific stress levels in the different psychotic groups, which can be explained at least partially by the psychotic symptomatology that they share in the acute episode. Moreover, confirming the initial hypothesis, our results show that stress is significantly higher in patients than in normal controls. Both data (schizophrenics vs. other psychotics, and schizophrenics vs. normal controls) agree with the paper of Norman and Malla [48], who reviewed several techniques used for the measurement of stress levels in schizophrenics.

Of relevance, in our view, is the fact that stressful situations collected in the FBF are not unusual life events, such as marriage and unemployment. On the contrary, stressful situations may appear continuously in the patient's daily life (e.g. conversations and quarrels). Norman and Malla [49] reported that daily stressors or hassles were more predictive of subjective stress than major life events.

The design of this investigation does not allow us to collect information concerning the course of self-perceived stress. Further work is needed to clarify this point, namely whether stress in schizophrenics tends to decrease compared to psychotics with a better prognosis, such as those diagnosed as having brief reactive psychoses. This fact may clar- 
ify the absence of significant differences in the complementary items of the FBF among the three diagnostic groups in the acute episode.

In conclusion, a few comments regarding the possible usefulness of the FBF in daily clinical practice: first of all, we would like to emphasize the fact that the complementary items of the FBF, so far regarded as describing coping mechanisms towards psychotic symptomatology, accurately reflect certain situations that the patient himself/herself perceives as stressful. Secondly, on our view the detection and quantification of these situations can be useful in order to obtain optimal conditions for applying rehabilitation techniques such as 'integrated psychological therapy' for schizophrenics designed by the group of Brenner et al. [50, 51]. Leff [52] has reviewed the efficacy of different interventions for schizophrenic patients in high-expressed-emotion environments, aiming at reducing stress level. Indeed, this kind of technique may be included among the environmental protectors, in the sense of Nuechterlein et al. [36] and Nuechterlein [53].

\section{Acknowledgement}

This paper has been supported with a grant of the Consejería de Cultura de la Junta de Castilla y León, in the Help Programm to Research Projects (VA-7/10/92).

\section{References}

1 Kraepelin E: Lehrbuch der Psychiatrie. Leipzig, Barth, 1909.

2 Bleuler E: Dementia praecox oder Gruppe der Schizophrenien; in Aschaffenburg G (ed): Handbuch der Psychiatrie. Leipzig, Deuticke, 1911.

3 Schneider K: Klinische Psychopathologie. Stuttgart, Thieme, 1959.

4 Andreasen NC: The Scale for the Assessment of Negative Symptoms (SANS). Iowa City. The University of Iowa, 1983.

5 Andreasen NC: The Scale for the Assessment of Positive Symptoms (SAPS). Iowa City. The University of Iowa, 1984.

6 Kay SR, Fiszbein A, Opler RA: The Positive and Negative Syndrome Scale (PANSS) for schizophrenia. Schizophr Bull 1987;13:261-276.

7 Chapman LJ: The early symptoms of schizophrenia. Br J Psychiatry 1966;112:225-251.

8 Chapman LJ, Chapman JP, Raulin ML: Body-image aberration in schizophrenia. J Abnorm Psychol 1978;87: 399-407.

9 McGhie A, Chapman J: Disorders of attention and perception in early schizophrenia. Br J Med Psychol 1961;34:103-116.

10 McGhie A, Chapman J, Lawson JS: The effect of distraction on schizophrenic performance: I. Perception and immediate memory. Br J Psychiatry 1965;111:383-390.

11 McGhie A: Attention and perception in schizophrenia; in Maher B (ed.): Progress in Experimental Personality Research. London, Academic Press, 1970, vol 4.

12 Gross G, Huber G, Klosterkötter J, Linz M: Bonner Skala für die Beurteilung von Basissymptomen (BSABS: Bonn Scale for the Assessment of Basic Symptoms). Berlin, Springer, 1987.

13 Gross G: The 'basic' symptoms of schizophrenia. Br J Psychiatry 1989;155(suppl 7):21-25.

14 Gross G, Huber G: Das Basissymptomkonzept idiopathischer Psychosen. Zentralbl Neurol 1989;252:655-673.

15 Huber G: Reine Defektsyndrome und Basisstadien endogener Psychosen. Fortschr Neurol Psychiatr 1966;34:409-426.

16 Huber G, Gross G, Schüttler R: Schizophrenie. Eine verlaufs- und sozialpsychiatrische Langzeitstudie. Berlin, Springer, 1979.

17 Huber G: Das Konzept substratnaher Basissymptome und seine Bedeutung für Theorie und Therapie schizophrener Erkrankungen. Nervenarzt 1983;54:23-32.

18 Klosterkötter J: The meaning of basic symptoms for the development of schizophrenic psychoses. Neurol Psychiatry Brain Res 1992;1:30-41.

19 Süllwold L: Symptome schizophrener Erkrankungen. Uncharakteristische Basisstörungen. Berlin, Springer, 1977.

20 Süllwold L: Schizophrenie, ed 2. Stuttgart, Kohlhammer, 1986.

21 Süllwold L, Huber G: Schizophrene Basisstörungen. Berlin, Springer, 1986. 
Süllwold L, Herrlich J: Providing schizophrenic patients with a concept of illness. An essential element of therapy. Br J Psychiatry 1992;16(suppl 18):129-132.

23 Jimeno Valdés A, Mateo I: El síndrome esquizofrénico. Una aportación a su diagnóstico diferencial y nuevos supuestos etiopatogénicos. Anal Acad Med Cir Vall 1982;20:183-191.

24 Jimeno Valdés A, Mateo I, Rios B, Morínigo A, López N: El Inventario Psicopatológico de Frankfurt. Presentación inicial. Actas Luso-Esp Neurol Psiquiatr 1984;12(2):115-120.

25 Jimeno Valdés A, Galindo A: El Inventario Psicopatológico de Frankfurt. Actas Luso-Esp Neurol Psiquiatr 1985;13(4):205-217.

26 Jimeno Valdés A, Cañas MT, Jimeno Bulnes N: El Inventario Psicopatológico de Frankfurt. Contribución al estudio de las psicosis productivas. Actas Luso-Esp Neurol Psiquiatr 1988;16(2):115-122.

27 Baum A, Grunberg NE, Singer JE: The use of psychological and neuroendocrinological measurements in the study of stress. Health Psychol 1982;1:217-236.

28 Dohrenwend BS: Life events as stressors: A methodological inquiry. J Health Soc Behav 1973;14:167-175.

29 Norman RMG, Malla AK: Stressful live events and schizophrenia. II. Conceptual and methodological issues. Br J Psychiatry 1993;162:166-174.

30 Vaughn CE, Leff JP: The influence of family and social factors on the course of psychiatric illness: A comparison of schizophrenic and depressed neurotic patients. Br J Psychiatry 1976;129:125-137.

31 Poljakov J: Schizophrenie und Erkenntnistätigkeit. Stuttgart, Hippokrates, 1973.

32 Jimeno Bulnes N, Jimeno Valdés A, Vargas ML: El síndrome psicótico y el Inventario de Frankfurt. Conceptos y resultados. Barcelona, Springer, 1996.

33 Spring B: Stress and schizophrenia: Some definitional issues. Schizophr Bull 1981;7:24-33.

34 Böker W, Brenner HD, Gerstner G, Keller F, Müller J, Spichtig L: Self-healing strategies among schizophrenics: Attempts at compensation for basic disorders. Acta Psychiatr Scand 1984;69:373-378.

35 Brenner HD, Böker W, Müller J, Spichtig L, Würgler S: On autoprotective efforts of schizophrenics, neurotics and controls. Acta Psychiatr Scand 1987;75:405-414.

36 Nuechterlein KH, Dawson ME, Ventura J, Gitlin M, Subotnik KL, Snyder KS, Mintz J, Bartzokis G: The vulnerability/stress model of schizophrenic relapse: A longitudinal study. Acta Psychiatr Scand 1994;89 (suppl 382):58-64.

37 Takai A, Uematsu M, Kaiya H, Inoue M, Ueki H: Coping styles to basic disorders among schizophrenics. Acta Psychiatr Scand 1990;82:289-294.

38 Zubin J, Spring B: Vulnerability - A new view of schizophrenia. J Abnorm Psychol 1977:86:103-126.

39 Zubin J, Steinhauer SR, Condray R: Vulnerability to relapse in schizophrenia. Br J Psychiatry 1992;161 (suppl 18):13-18.

40 Jimeno Bulnes N: Estudio clínico y psicopatológico estructural de las psicosis delirantes, especialmente tóxicas. Tesis Doctoral, Universidad de Valladolid, 1993

41 Jimeno Bulnes N: Drogas y enfermedad mental. Un estudio de las esquizofrenias y psicosis tóxicas. Valladolid, Secretariado de Publicaciones de la Universidad de Valladolid, 1995.

42 Vargas ML: Seguimiento psicopatológico de una cohorte de enfermos psicóticos pertenecientes a tres grupos diagnósticos. Estabilidad y aportaciones del Inventario Piscopatológico de Frankfurt. Tesina de Licenciatura, Universidad de Valladolid, 1993.

43 Vargas ML, Jimeno Valdés A, Jimeno Bulnes N: Estabilidad test-retest y validez concurrente con el AMDP del Inventario Psicopatológico de Frankfurt en tres grupos de enfermos psicóticos. Actas 17 Reunión Soc Esp Psiquiatr Biol. Madrid, ELA, 1994, pp 352-360.

44 Vargas ML, Jimeno Bulnes N, Jimeno Valdés A: Los síntomas básicos como indicatores cognitivos de vulnerabilidad a la esquizofrenia. Psiquiatr Biol 1995;2:63-70.

45 Jimeno Bulnes N: Aportación del Inventario Psicopatológico de Frankfurt al estudio de los síndromes psicóticos. Tesina de Licenciatura, Universidad de Valladolid, 1988.

46 Jimeno Bulnes N, Jimeno Valdés A, Conde V: Aportación del Inventario Psicopatológico de Frankfurt en el estudio psicopatológico del síndrome delirante. Actas 15 Reunión Nac Soc Esp Psiquiatr Biol. Madrid, ELA, 1991, vol 1, pp 51-82.

47 Jimeno Valdés A, Jimeno Bulnes N, Medina MC: Vulnerabilidad para las psicosis idiopáticas. Síntomas psicóticos básicos y su especificidad en la mujer. Inform Psiquiátr 1994;135-136:115-122.

48 Norman RMG, Malla AK: Stressful life events and schizophrenia. I. A review of the research. Br J Psychiatry 1993;162:161-166.

49 Norman RMG, Malla AK: Subjective stress in schizophrenic patients. Soc Psychiatry Psychiatr Epidemiol 1991;26:212-216.

50 Brenner HD, Hodel B, Roder V, Corrigan PW: Treatment of cognitive dysfunctions and behavioral deficits in schizophrenia. Schizophr Bull 1992;18:21-26.

51 Brenner HD, Roder V, Hodel B, Kienzle N, Reed D, Lieberman R: Integrated Psychological Therapy for Schizophrenic Patients. Bern, Huber, 1994.

52 Leff J: Stress reduction in the social environment of schizophrenic patients. Acta Psychiatr Scand 1994;90 (suppl 384):133-139.

53 Nuechterlein KH: Vulnerability models for schizophrenia: State of the art; in Häfner H, Gattaz WF, Janzarik W (eds): Search for the Causes of Schizophrenia. Berlin, Springer, 1987, pp 297-316. 